\title{
Continuous Inferior Alveolar Nerve Block Using an Indwelling Catheter and Inferior Maxillary Artery Embolization for the Management of Atypical Trigeminal Neuralgia
}

\author{
Samer Abdel-Aziz, Ahmed Ghaleb \\ Department of Anesthesiology and Pain Medicine, University of Arkansas for Medical Sciences, Little Rock, USA. \\ Email: samer.abdelaziz@gmail.com
}

Received July $5^{\text {th }}, 2103$; revised August $6^{\text {th }}, 2013$; accepted September $1^{\text {st }}, 2013$

Copyright (C) 2013 Samer Abdel-Aziz, Ahmed Ghaleb. This is an open access article distributed under the Creative Commons Attribution License, which permits unrestricted use, distribution, and reproduction in any medium, provided the original work is properly cited.

\begin{abstract}
A 40-years-old female patient with severe right facial pain with a throbbing component along the mandibular division of the trigeminal nerve resistant to medical management. Continuous inferior alveolar nerve block with local anesthetics using an indwelling catheter provided a complete pain resolution for the patient for 2 weeks, after which the catheter got infected and was removed. A trial of balloon occlusion of the right internal maxillary artery provided complete resolution of the throbbing component of the patient's pain. This was followed by permanent embolization with multiple coils.
\end{abstract}

Keywords: Trigeminal Neuralgia; Inferior Alveolar Nerve Block; Inferior Maxilary Artery Embolization

\section{Introduction}

Trigeminal neuralgia (TN) can cause severe pain resistant to medical management. Several interventional pain and surgical procedures are available and individualized based on the patient's condition. We report a case with severe trigeminal neuralgia pain resistant to medical management in which we used two uncommon treatment modalities that provided excellent pain relief for our patient; continuous inferior alveolar nerve block with local anesthetics using an indwelling catheter and internal maxillary artery embolization.

\section{Case Report}

A 40-year-old female referred to our pain clinic complaining of right facial pain along the mandibular division of the trigeminal nerve for 4 years. She describes her pain as constant throbbing burning pain with occasional electric-like sensation. The pain is $8 / 10$ in severity. It occasionally goes up to $10 / 10$ and gets severe enough for her to think about killing herself. It affects her daily activities, occasionally keeping her in bed all day. It gets worse in the evening and gets better when she applies ice on her face and after she takes her atenolol pill which she takes twice a day for hypertension. The pain was initially thought to be of dental cause which resulted in her having multiple dental procedures without improvement. Over the past 4 years, she tried multiple medications including Ibuprofen, gabapentin, carbamazepine, cyclobenzaprine with minimal relief. She had and MRI and MRA of her face and neck to exclude any mass effect or vascular compression of the nerve, all were reported normal. We initially started her on topiramate and amitriptyline with oxycodone-acetaminophen pills for breakthrough, this improved her pain to $5 / 10$. However it was still severe, affecting her ability to perform her daily activities. As medical management failed to provide sufficient pain relief, decision was made to proceed with a nerve block. Right inferior alveolar and lingual nerve blocks were performed by injecting $5 \mathrm{ml}$ of lidocaine 1\%, $1 \mathrm{ml}$ of triamcinolone $(40 \mathrm{mg} / \mathrm{ml})$ and $5 \mathrm{ml}$ of bupivacaine $0.5 \%$. The patient reported complete resolution of pain for 2 days only, so decision was made to proceed with placement of an indwelling catheter that the patient 
can dose herself with a local anesthetic like bupivacaine $0.5 \%$. The catheter was placed close to the right inferior alveolar nerve using an epidural needle set and was secured in place with Nylon sutures. The catheter placement was successful and provided excellent pain relief for the patient however, one month later the catheter dislodged from its placed and had to be replaced. Two weeks after the catheter replacement it got infected and had to be removed. After the catheter removal the patient experienced severe pain again, at this point we decided to refer her for interventional radiology for an angiogram and temporary occlusion of her right internal maxillary artery as this might help with her throbbing pain. A ballon catheter was advanced into the right internal maxillary artery and was kept inflated for 10 minutes, the patient reported complete resolution of her throbbing pain. Since the patient passed the ballon test, embolization of the artery with multiple detachable and push coils was performed. After the artery embolization the patient reported complete resolution of her throbbing pain. She still reports having some burning pain which is well controlled with the topiramate and amitriptyline. On her last clinic visit she reported a pain score of 0/10.

\section{Discussion}

Trigeminal neuralgia (TN) is a sudden, unilateral, severe, brief, recurrent episodes of pain in the distribution of one or more branches of the trigeminal nerve [1]. It is the most common form of cranial neuralgia [2,3], with an incidence of 4.3 per 100,000 persons per year, with a slightly higher incidence for women (5.9 per 100,000) compared with men $(3.4$ per 100,000$)$ [4]. The gender ratio of prevalence in women to men is approximately 2:1 [5].

In the large majority of TN patients, the clinical examination, imaging studies and laboratory tests are unremarkable (classic TN). However, in a smaller group, the signs and symptoms of TN are secondary to another disease process affecting the trigeminal system (symptomatic TN) [6,7]. Both dental and medical professionals often misdiagnose the disorder, potentially resulting in unnecessary dental extractions or inappropriate prescription of drugs.

The cause of trigeminal neuralgia has not been definitively established. However, the most prevalent cause is mechanical compression, generally by an artery (superior cerebellar artery or one of its branches) or a tumor, of the trigeminal root as it exits the brain stem [8]. Also, following trauma, regenerating nerve fibers become relatively depolarized and physiologically more excitable. Spontaneous action potentials may originate from multiple sites and a single action potential may evoke sustained discharges [6].
Optimal treatment of TN remains challenging, as each clinical situation can vary significantly. Patients who suffer from TN have a number of treatment modalities to consider, and treatments should be tailored to the individual situation. Conservative management with drug therapy is always the first-line treatment. When drugs are not efficacious or produce intolerable adverse effects, interventional pain treatment or surgery is considered. Carbamazepine has been used for many decades in the treatment of TN, and it is the drug of choice [9,10]. Other medications with reported efficacy include oxcarbazepine, baclofen, and lamotrigine [11-13]. Topiramate, gabapentin, pregabalin, and levetiracetam have also shown success in treating TN [11].

Peripheral techniques like cryotherapy, neurectomies, peripheral acupuncture, peripheral radiofrequency thermocoagulations (RFTs) and a variety of injections, such as alcohol, phenol and streptomycin have been described as treatment modalities for TN. Percutaneous procedures at the level of the Gasserian ganglion which involve the insertion of a cannula through the foramen ovale into the trigeminal ganglion have also been used. The ganglion can then be lesioned using heat (RFTs), injection of glycerol, or mechanical compression by a balloon.

Microvascular decompression (MVD) and gamma knife surgery (GKS) are surgical options available to patients with TN. MVD has been widely used based on the theory that vascular compression of the trigeminal nerve is responsible for TN $[14,15]$. A retrospective review of patients with TN who had undergone MVD showed that $71 \%$ reported complete pain relief 10 years after surgery [16]. GKS is a noninvasive stereotactic radiosurgical technique that utilizes a focused beam of radiation to target the root of the trigeminal nerve. Pain relief obtained from GKS is delayed and usually occurs about 2 weeks later. Initial good pain relief can be achieved in $80 \%$ of patients $[17,18]$. However, there is a risk of recurrence after 1 year [17].

Continuos mandibular nerve block with local anesthetics using an indwelling catheter to control TN pain is uncommon but has been reported [19]. It allows continuous or intermittent injection of local anesthetics when necessary. It is more convenient than repeated nerve blocks as it eliminates the use of a needle and can be dosed by the patient. It is also reversible and safe. It provided complete resolution of pain and satisfaction for our patient. However as described in our case it is highly vulnerable to infection and dislodgment and is difficult to maintain for a long period of time. For this reason we recommend its use as a temporary measure to control pain until a more definitive permanent procedure is undertaken.

Embolization of the internal maxillary artery is used to 
control epistaxis and life threatening bleeding following facial trauma [20,21]. However, its use for trigeminal neuralgia is uncommon. One study reported the use of maxillary embolization in 76 patients with trigeminal neuralgia with achievement of absolute improvement [22]. Since in our case the patient's pain had a throbbing component we thought she might benefit from internal maxillary artery embolization. We first used a balloon trial to test if artery occlusion will provide pain resolution, when the patient passed the trial we embolized the artery, the patient reported complete resolution of the throbbing pain. The procedure is safe as the area supplied by the artery has collateral blood supply. We recommend this procedure for patients with throbbing pain not controlled by medical management with emphasis on a balloon trail before permanent occlusion.

\section{Conclusion}

Treatment of TN should be tailored to the individual situation. Several interventional pain and surgical procedures are available to treat pain resistant to medical management. Continuous mandibular or alveolar nerve blocks with local anesthetics using an indwelling catheter can provide complete pain resolution and patient satisfaction but with a risk of infection on long term use. Internal maxillary embolization is a permanent treatment modality to be considered in patients with a throbbing pain.

\section{REFERENCES}

[1] H. Merskey and N. Bogduk, "Classification of Chronic Pain. Descriptors of Chronic Pain Syndromes and Definitions of Pain Terms," 2nd Edition, IASP Press, Seattle, 1994.

[2] J. S. Koopman, J. P. Dieleman, F. J. Huygen, M. de Mos, C. G. Martin and M. C. Sturkenboom, "Incidence of Facial Pain in the General Population,” Pain, Vol. 147, No. 1-3, 2009, pp. 122-127. http://dx.doi.org/10.1016/j.pain.2009.08.023

[3] V. R. Aggarwal, G. J. Macfarlane, T. M. Farragher and J. McBeth, "Risk Factors for Onset of Chronic Oro-Facial Pain-Results of the North Cheshire Oro-Facial Pain Prospective Population Study,” Pain, Vol. 149, No. 2, 2010, pp. 354-359. http://dx.doi.org/10.1016/j.pain.2010.02.040

[4] F. Yoshimasu, L.T. Kurland and L. R. Elveback, "Tic Douloureux in Rochester, Minnesota, 1945-1969,” Neurology, Vol. 22, No. 9, 1972, pp. 952-956. http://dx.doi.org/10.1212/WNL.22.9.952

[5] S. Katusic, D. B. Williams, C. M. Beard, E. J. Bergstralh and L. T. Kurland, "Epidemiology and Clinical Features of Idiopathic Trigeminal Neuralgia and Glossopharyngeal Neuralgia: Similarities and Differences, Rochester, Minnesota, 1945-1984," Neuroepidemiology, Vol. 10, No. 5-6, 1991, pp. 276-281. http://dx.doi.org/10.1159/000110284
[6] D. Bowsher, "Trigeminal Neuralgia: An Anatomically Oriented Review,” Clinical Anatomy, Vol. 10, No. 6, 1997, pp. 409-415.

http://dx.doi.org/10.1002/(SICI)1098-2353(1997)10:6<40 9::AID-CA7>3.0.CO;2-J

[7] A. J. Brito, “Trigeminal Neuralgia,” Acta Médica Portuguesa, Vol. 12, No., 1999, pp. 187-193.

[8] F. G. Barker, P. J. Jannetta, R. P. Babu, et al., "LongTerm Outcome after Operation for Trigeminal Neuralgia in Patients with Posterior Fossa Tumors,” Journal of Neurosurgery, Vol. 84, No. 5, 1996, pp. 818-825. http://dx.doi.org/10.3171/jns.1996.84.5.0818

[9] S. C. Bagheri, F. Farhidvash and V. J. Perciaccante, "Diagnosis and Treatment of Patients with Trigeminal Neuralgia,” The Journal of the American Dental Association, Vol. 135, No. 12, 2004, pp. 1713-1717.

[10] P. J. Wiffen, S. Collins, H. J. McQuay, D. Carroll, A. Jadad and R. A. Moore, "Anticonvulsant Drugs for Acute and Chronic Pain,” The Cochrane Database Systematic Reviews, Vol. 20, No. 3, 2005, pp.

[11] G. Cruccu, G. Gronseth, J. Alksne, et al., "AAN-EFNS Guidelines on Trigeminal Neuralgia Management,” European Journal of Neurology, Vol. 15, No. 10, 2008, pp. 1013-1028.

http://dx.doi.org/10.1111/j.1468-1331.2008.02185.x

[12] G. H. Fromm, C. F. Terrence and A. S. Chattha, "Baclofen in the Treatment of Trigeminal Neuralgia: Double-Blind Study and Long-Term Follow-Up,” Annals of Neurology, Vol. 15, No. 3, 1984, pp. 240-244. http://dx.doi.org/10.1002/ana.410150306

[13] J. M. Zakrzewska, Z. Chaudhry, T. J. Nurmikko, D. W. Patton and E. L. Mullens, "Lamotrigine (Lamictal) in Refractory Trigeminal Neuralgia: Results from a DoubleBlind Placebo Controlled Crossover Trial,” Pain, Vol. 73, No. 2, 1997, pp. 223-230. http://dx.doi.org/10.1016/S0304-3959(97)00104-8

[14] P. Janetta, "Trigeminal Neuralgia: Treatment by Microvascular Decompression,” In: R. Wilkins and S. Regachary, Eds., Neurosurgery, McGraw-Hill, New York, 1996, pp. 3961-3968.

[15] J. Hai, S. T. Li and Q. G. Pan, "Treatment of Atypical Trigeminal Neuralgia with Microvascular Decompression,” Neurology India, Vol. 54, No. 1, 2005, pp. 53-56. http://dx.doi.org/10.4103/0028-3886.24706

[16] Z. Sarsam, M. Garcia-Finana, T. J. Nurmikko, T. R. Varma, P. Eldridge, "The Long-Term Outcome of Microvascular Decompression for Trigeminal Neuralgia,” British Journal of Neurosurgery, Vol. 24, No. 1, 2010, pp. 8-25. http://dx.doi.org/10.3109/02688690903370289

[17] A. A. Dhople, J. R. Adams, W. W. Maggio, S. A. Naqvi, W. F. Regine and Y. Kwok, "Long-Term Outcomes of Gamma Knife Radiosurgery for Classic Trigeminal Neuralgia: Implications of Treatment and Critical Review of the Literature Clinical Article,” Journal of Neurosurgery, Vol. 111, No. 2, 2009, pp. 351-358. http://dx.doi.org/10.3171/2009.2.JNS08977

[18] J. Regis, P. Metellus, M. Hayashi, P. Roussel, A. Donnet and F. Bille-Turc, "Prospective Controlled Trial of Gam- 
ma Knife Surgery for Essential Trigeminal Neuralgia,” Journal of Neurosurgery, Vol. 104, No. 6, 2006, pp. 913924. http://dx.doi.org/10.3171/jns.2006.104.6.913

[19] M. Umino, H. Kohase, S. Ideguchi and N. Sakurai, "LongTerm Pain Control in Trigeminal Neuralgia with Local Anesthetics Using an Indwelling Catheter in the Mandibular Nerve,” The Clinical Journal of Pain, Vol. 18, No. 3, 2002, pp. 196-199. http://dx.doi.org/10.1097/00002508-200205000-00010

[20] J. E. Cohen, S. Moscovici, J. M. Gomori, R. Eliashar, J. Weinberger and E. Itshavek, "Selective Endovascular Embolization for Refractory Idiopathic Epistaxis Is a Safe and Effective Therapeutic Option: Technique, Complications, and Outcomes," Journal of Clinical Neuroscience,
Vol. 19, No. 5, 2012, pp. 687-690.

http://dx.doi.org/10.1016/j.jocn.2011.08.019

[21] S. T. Shuker, "The Immediate Lifesaving Management of Maxillofacial, Life-Threatening Haemorrhages due to IED and/or Shrapnel Injuries: 'When Hazard Is in Hesitation, Not in the Action', Journal of Cranio-Maxillofacial Surgery, Vol. 40, No. 6, 2012, pp. 534-540. http://dx.doi.org/10.1016/j.jcms.2011.09.005

[22] V. Novak, P. Bosniakovic, S. Ristic, A. Kostic, B. Jelenkovic and M. Novak, "Occlusion of Maxillary Artery in Treatment of Trigeminal Neuralgia,” Medicinski Pregled, Vol. 65, No. 7-8, 2012, pp. 281-284. http://dx.doi.org/10.2298/MPNS1208281N 